Article

\title{
Policies, Politics, and Paradigms: Healthy Planning in Australian Local Government
}

\author{
Anthony McCosker*, Anne Matan and Dora Marinova ${ }^{(D)}$ \\ Curtin University Sustainability Policy (CUSP) Institute, Curtin University, Perth 6102, Australia; \\ anne.matan@curtin.edu.au (A.M.); d.marinova@curtin.edu.au (D.M.) \\ * Correspondence: a.mccosker@postgrad.curtin.edu.au; Tel.: +61-8-9266-9030
}

Received: 31 January 2018; Accepted: 23 March 2018; Published: 29 March 2018

\begin{abstract}
Local government in Australia is critically positioned to provide built environment initiatives that respond to the increasing prevalence of non-communicable diseases (NCD), climate change, and various other human and ecological health considerations. However, action on the ground has not been as widespread as might be expected, particularly in improving community health. This research explores the barriers to and enablers of the implementation of healthy planning and active living initiatives through in-depth interviews with healthy planning and active living advocates. Advocates are seen to promote healthy planning in relatively weak policy settings, where politicised, largely reactive decisions by individual politicians or practitioners are the main determinants of project success. The most important factor affecting project uptake and implementation is how the 'problem' of healthy planning, or what might be considered a healthy planning paradigm, is presented. Such a paradigm includes a strong reliance on the co-benefits of projects; it is also subject to the way that healthy planning is communicated and framed. Potential problems around such a setting are subsequently examined, identifying the potential reasons for the slow delivery of healthy planning.
\end{abstract}

Keywords: planning; health; active living; multiple streams analysis; Australia; local government

\section{Introduction}

\subsection{Human Health, Planetary Health and the Built Enviornment}

The close link between the health of the human population and that of the planet [1] is recognised through the concept of planetary health [2-5]. Such a concept is not new; indigenous societies have long understood this relationship [6,7] through the perspective that "human health cannot be seen separately from ecosystems" [8] (p. 301). Today, however, given the increasing rates of urbanisation [9], this link is most obviously manifested in the built environment [10-13]. For instance, particularly in higher income societies, the influence of the built environment on planetary health has become evident through the effects of the development of low density, car-dependent suburbs with limited land use integration [14]. Such land-use patterns are associated with impacts that are placing an increasing burden on the natural environment $[15,16]$ as well as posing significant social [17-19] and economic [20] challenges. These land-use patterns also offer limited opportunities to socialise locally or participate in active forms of transport [14], while also leading to higher greenhouse gas emissions [11]; they are also due largely to increased reliance on motorised transport [21-23]. The impacts on human health and well-being are expected to be further exacerbated by climate change [24,25], particularly for indigenous people [26] and those in lower income countries [27]. So, while managing the built environment might currently have an implicit goal of improving community and individual health [28], as the prevalence of non-communicable diseases (NCDs) continues to rise and the impacts of climate change worsen, the role of place managers, such as local government (LG) and LG practitioners, will 
gain even greater importance [25]. There is a significant opportunity to address these problems in a coordinated manner, through changes to the built environment $[20,24]$.

Given this opportunity, and the associated benefits that such actions can have [12], urban planning attention has recently shifted focus [13], moving towards the encouragement of active and public transport [29], such as through land-use planning [30,31] and behaviour change programmes [32-36]. However, while there has been "exponential growth in research, teaching, and policy related to health and the built environment" ([37] p. 1542; [12]), and the imperative for action is growing [38], efforts to make more healthy, sustainable built environments are far from ubiquitous. This might be a result of the complexities of "translating that evidence into policy and practice at multiple levels" [39] (p. 1), with such initiatives proving "hard to activate on the ground" ([31] p. 2; [18]) and subsequently resulting in the relatively slow uptake of healthy planning principles. In a comprehensive Australian review [40,41], these principles were found to include "getting people active ... connecting and strengthening communities ... and providing healthy food options" [42] (p. 19). The focus of this study is planning that addresses the first principle, though the three are noted as interconnected. With these three principles in mind, healthy planning can be defined as "planning for people and how they use different environments"; in doing so, it "places the needs of people and communities at the heart of the urban planning process and encourages decision-making based on considerations of human health and well-being" ([43] p. 385; [44]). Additionally, active living initiatives are those that encourage "a way of life where people integrate organised or informal physical activity into their daily routines" ([45] p. 6; [46]). The slow uptake of healthy urban forms is particularly evident in Australia [47], where built environments that are detrimental to health are retained or continue to be created [48]. Indeed, in many contexts, land use and transport planning work against the provision of health-supportive environments [23].

Given that there is a strong evidence base for change, yet relatively little difference is evident on the ground, the need to explore factors influencing the implementation of healthy planning and active living initiatives is clear. To date, greater academic focus has necessarily been afforded to establishing the causal linkages between urban form, transport choices, and human health [13,49-51]. Although town planning had its origins in efforts to improve public health [52,53], the two professions developed independently for a long time, and their relationship has only recently re-emerged. With these linkages now established [12,41], the opportunity (and imperative) for academic attention to turn towards the implementation of initiatives that improve public and planetary health transpires [54].

\subsection{Significance of the Study}

Having such an imperative in mind, this study aims to identify the barriers to and enablers of the uptake and implementation of healthy planning and active living initiatives. This research focusses at a LG level, as although issues such as NCDs present a global challenge, addressing these challenges ultimately requires local action [18]. The key role of LG in addressing such issues has been noted [55,56], but limited academic attention has been focussed on this level of governance to date. Attention has more commonly been afforded to healthy planning at the state government level, perhaps due to states' legislative power over LGs [57], or given Australian states' traditional role in providing for acute health care treatment such as through hospitals. Yet the 'day-to-day' roles of planning and policy implementation are generally delegated to LG in Australia [58], which are important considerations given the role that the local setting can play in community and individual health [59]. Therefore, while states might set a general direction, and are important actors through their legislative power over LG, LGs can ultimately be seen in many instances as being responsible for the delivery of healthy communities [56]. By focussing on LG, this research provides an examination of this important level of governance, and addresses the practical issue of initiative implementation (or lack of implementation), which is a consideration that is often overlooked in public health policy [14,54].

In Australia, practitioner knowledge and perspectives have been sought regarding climate change impacts on human health [25], agenda setting in healthy planning at the state level [47], the feasibility 
and effectiveness of obesity prevention programmes [60], and healthy planning by LG. Yet relatively less attention has been afforded to the perspectives of advocates in this space, particularly with a focus at the local level. However, advocacy has played an active role in advancing healthy planning efforts in Australia [56,61], and such perspectives are important.

\subsection{Current State of Research}

Few studies have explicitly explored the concept of barriers and enablers with regard to healthy planning and active living policy or implementation, particularly within an Australian LG setting [14,61-63]. However, healthy planning literature does offer insights into settings that might encourage or discourage healthy planning and active living initiative uptake and implementation. The existing research context is explored briefly below.

Barriers to integrated planning for health in the Australian Victorian state context have been noted as including tokenistic consultation between departments, a politicised (state) planning system, insufficient resources, and difficulty in implementing even established policies [14]. A commonly identified barrier at the state scale is the siloed operation between departments [14,64]. A lack of incentives for practitioners with regard to collaboration [18] or the consideration of social determinants of health (Note 1 in Appendix A) [62] can also inhibit project implementation. At a LG level, practitioner perceptions of powerlessness to instigate change can present a barrier to action [63]. Further, skepticism by practitioners regarding the viability of land use planning's ability to address obesity concerns [60], as well as limited practitioner knowledge regarding the social determinants of health [62] and the health impacts of climate change [25], could all potentially prohibit project adoption or implementation. The organisational structure of LGs can also limit healthy planning uptake and implementation [61].

Limited consideration of health in state policies and poor integration between these policies can lead to ad hoc, developer-led planning [14]. This policy setting can at the same time be prohibitively complex [64,65], which can make LG practitioners reluctant to add healthy planning policies to an already complex setting [63]. Competing priorities of LGs and limited funding can also be prohibitive to healthy planning and active living initiatives $[61,66]$.

In terms of enabling factors for healthy planning, the benefits of integrated planning and thinking have been noted internationally [18] as well as in an Australian setting [67]. Australian guidance for practitioners operating in the healthy planning field also notes the importance of integration including "working across sectors, roles and responsibilities, regulations, policies and programme delivery" [56] (p. 12). The importance of sharing "ownership of the processes and the end goals, and having a clear understanding of who does what during implementation" is also noted [56] (p. 12). A supportive policy structure from higher levels of government than LG can encourage such initiatives, with an integrated approach again noted to have importance [18].

The health impact assessment (HIA) of plans and projects $[68,69]$ is identified as a possible avenue to integrated planning at the state level [14], and for greater consideration to be given to social determinants of health by LG practitioners [62]. Healthy planning efforts are also supported through "formal intersectoral governance structures", whose arrangements include LG as well as those at a regional level, and informal, (state level) interdepartmental relationships [14] (p. 7). The importance of intersectoral collaboration has also been identified at a New South Wales state level [64] and at the Victorian LG level [62], and the value of partnership formation in the healthy planning field is well recognised $[56,61,64]$. The need for a suitably skilled public sector workforce [14] in turn makes education, training, and professional development important considerations in furthering healthy planning [56,70]. Practitioners have indicated that "more practical information about effective interventions" could promote action in this field [62], particularly where interventions (and evidence stemming from these interventions) are developed locally [63]. Localised research into causal links between communities' built and social settings and their health can assist project implementation [62], particularly where external funding is provided to LG, although current funding mechanisms in Australia raise concerns over their continuity [63]. A strong mandate for LG action-whether from 
bottom-up, community lobbying [63] with a focus on the good news value of projects, or from top-down, government-led policies [61] — can also assist project uptake and implementation.

Within this summary of barriers to and enablers of considerations of healthy planning, a strong focus is evident at the state scale. Few studies focus solely on identifying supportive or prohibitive factors to project implementation, particularly at the LG level. Further, limited studies reflect the multidisciplinary nature of the healthy planning field, which is influenced by a diverse array of actors in various roles operating at various levels. This research aims to address these research gaps, as discussed below.

\section{Materials and Methods}

Approaches that allow for an understanding of the "policy world" can help to bridge the "research translation gap" between researchers and practitioners [71]. Without a grasp of this policy world, technical solutions alone are unlikely to benefit or influence practice [54]. It is important, then, for healthy planning research to engage in political science [39]. Yet the policy world is complex and influenced by various actors across multiple disciplines, as well as by numerous "political, social, cultural and historical factors" [14] (p. 3). One framework that enables these factors to be examined is multiple streams analysis (MSA), in which policy, problem, and political considerations are each seen to have influence over decision-making and policy uptake [72]. Adopting an MSA framework can allow for a more nuanced understanding of decision-making processes to emerge, avoiding the linear model of the stages heuristic theory [54]. Its relevance and applicability [61] justify the adoption of the MSA framework in this study, as discussed below.

\subsection{Multiple Streams Analysis (MSA)}

An MSA framework describes the conditions that must come together in order for policy action to occur [72]. Under this model, the conditions (or streams) include problems, politics, and policies [72]. The problem stream relates to how decision-makers view a problem, or whether an issue is even viewed as a problem that is necessary to address [23]. The policy stream relates to policy options, and influences the range of policy responses that are available to decision-makers [72]. Lastly, the politics stream relates to public opinion about an issue [73]. The streams exist (or at least act) independently [74], until they are brought together to form a "policy window" [75]. The policy window is an opportunity for the policy setting to change: at this stage, "a problem has been recognized, there is an acceptable solution available and the political climate is right" [76] (p. 114). Such a window presents an opportunity for a policy entrepreneur (an individual or organisation) to intervene and influence the policy process ([76] p. 114; [72]).

The use of this framework helps avoid some of the criticisms of rational models of policy processes [54,77], and is well suited to complexity [78]. The framework is applicable to municipal settings [73], and has been posited as a framework to guide health research on urban planning [23]. MSA has been used in examining drivers and barriers to local health policy development in the Netherlands [76], and agenda setting frameworks such as MSA have been noted to have relevance to community health in an Australian LG context [62]. Importantly, while it is most commonly applied to agenda-setting, an MSA approach can also be used to examine policy application and implementation [79]. The chance of policy implementation has been found to depend on the three streams, as well as the governance structures around them [80], which is a relevant consideration given the contested nature of governance in this field between state and LG levels [57]. The MSA model has also been built around examining implementation, such as through an expansion of the number of metaphorical streams used [81], although the original three streams are "well suited to analyse how policies are applied and implemented across space and over time" [79] (p. 507). This has seen the recent use of MSA in examining implementation $[57,61,80,81]$, with the problem and political streams noted as having particular relevance [79]. 


\subsection{Sample}

A snowball sampling method $[66,82]$ was employed to identify and recruit potential interviewees. Initial participants were recruited from the researchers' professional networks, and potential new interviewees were identified during interviews with these key informants.

Selection criteria limited participants to healthy planning and active living advocates in Australia. Advocates were defined as those who had made a significant and recent (within the last three years) contribution to: (1) practice, and (2) public debate around healthy planning and active living initiatives at the LG level. The participation of advocates was specifically sought, as the healthy planning and active living field has noted political commitment for changes that address health inequalities to be of particular importance [14]. Data collection proceeded until data saturation was deemed to have occurred [66,82], resulting in 28 participants.

Of these 28 participants, 11 were female and 17 were male, with $46.4 \%$ working in New South Wales $(n=13), 28.6 \%$ working in Western Australia $(n=8), 14.3 \%$ working in South Australia $(n=$ 4), and $10.7 \%$ working in Victoria $(n=3)$. There were no interviewees from Queensland, Tasmania, the Northern Territory, nor the Australian Capital Territory. This sample (see also Figure 1) reflects the biases of the key informant, snowball sampling method, whereby key informants tended to identify additional potential interviewees operating within their own state. Nevertheless, in addressing this bias towards certain states, data were corroborated with data from respondents across states.

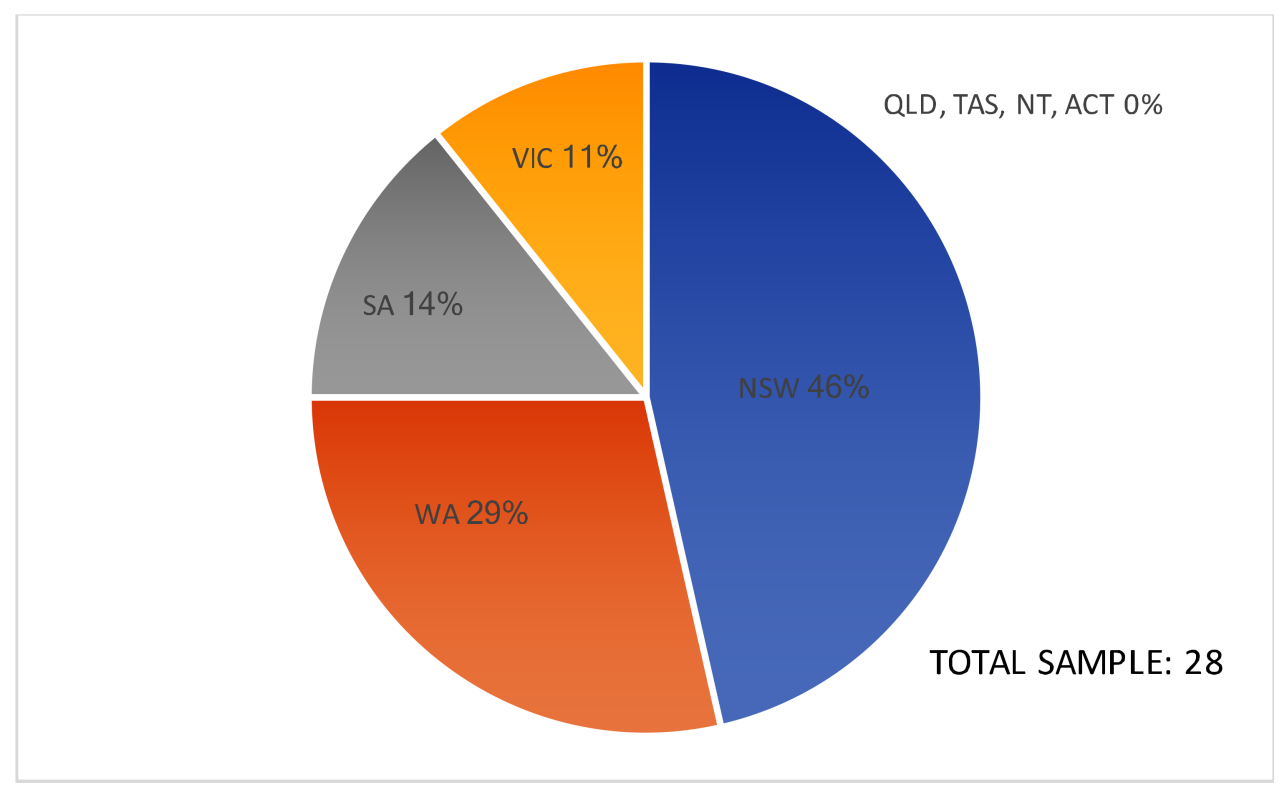

Figure 1. Australian interview sample.

Given the collaboration required by such initiatives, including the significant role of non-governmental actors [14] and the need for intersectoral partnerships [83], advocates were sought from a broad range of roles from both the community/public health $(n=13$ or $46.4 \%)$ and built environment $(n=15$ or $53.6 \%)$ professions. Advocates are identified throughout this paper based on their role in the built environment (BE) or community health $(\mathrm{CH})$ field. Participants' employment included government roles with a regional focus ( $n=6$ or $21.4 \%$ ), within LG $(n=5$ or $17.9 \%)$, and at a state level $(n=4$ or $14.3 \%)$. Participants also had roles in academia ( $n=4$ or $14.3 \%)$, in non-governmental organisations ( $n=3$ or $10.7 \%$ ) and in the private sector $(n=3$ or $10.7 \%)$. Additionally, one participant had roles in academia as well as at regional and LG levels (3.6\%), another participant had roles at both the regional and LG levels, and one had regional and academic positions. 


\subsection{Data Collection}

Twenty-eight semi-structured, in-depth interviews were undertaken with healthy planning and active living advocates. The semi-structured interviews offered flexibility, allowing concepts that were not included in the original interview questionnaire "but which may provide further insight to the research question" to be explored [63] (n.p.). Interviews were audio recorded and transcribed, with transcripts checked by the respondents to ensure accuracy and allow for clarification or additional information to be provided.

\subsection{Data Analysis}

Upon approval from respondents, transcripts were analysed using data analysis software NVivo 11. Coding was initially informed by sensitising concepts from MSA. Although MSA has been noted as a relevant lens through which to view planning efforts to address NCDs [23], and its advantages include adaptiveness [84] and an applicability to examining implementation (refer to Section 2.1), the framework was employed as a sensitising concept [85]. The use of sensitising concepts helped to ensure flexibility in coding, allowing for emergent themes to be identified and minimising the likelihood that theories of the MSA framework would be forced onto the data [85].

Thematic analysis of transcripts was undertaken iteratively [86]. Data were analysed immediately following approval by the respondents, with emergent themes validated against existing data and MSA (as a sensitising concept), with this phase then informing subsequent interviews $[63,86,87]$. Once data saturation was reached, the identified themes were reviewed, defined [86], and coded as enablers or barriers $[14,88,89]$, with some themes noted to have the potential to act as both.

\section{Results}

This section provides an overview of the themes that were commonly identified by healthy planning and active living advocates as either barriers or enablers (or both) to initiative uptake and implementation, namely policies and politics. The policy setting in which these initiatives occurred at the LG scale is examined, as are relevant political considerations. As neither of these considerations were identified as being a prohibitive barrier or consistent enabler to initiative uptake, the central role of the way that the healthy planning 'problem' is conveyed is then examined.

\subsection{Policies}

The policy and legislative setting has been identified as being central to supporting healthy planning in Australia, including at the state [47] and LG levels [90]. This section examines themes regarding the policy setting, including barriers and enablers stemming from state-level health and planning policy, policies (not necessarily related to health or planning) that impact LG functioning, and health and planning policies at the LG level.

\subsubsection{State Policies-Planning and Health}

Both health and built environment advocates identified a view that "the ultimatum for healthy built environment policy needs to come from above local government" [BE1]. Having state-level impetus was generally considered more effective than bottom-up or LG-led policy, given its potential for more widespread population health benefits [CH1], yet the dominant legislative role of the state level over LG made the latter reliant on both health and planning policy from above [BE2]. Such a situation could act as a barrier where a state legislative framework was not supportive of healthy planning, resulting in a lack of "sufficient autonomy" for LG in policy implementation due to "interference at a state level" [BE3].

However, respondents generally identified the emergence of a more supportive state legislative setting that enabled healthy planning implementation, which has been particularly evident over the last ten years [CH1, CH2]. Commonly identified enablers were state public health legislation 
mandating for LGs to produce health plans [CH3, BE3] and opportunities for state planning legislation to include concepts of health [BE4, BE5, BE6, CH2]. For instance, the introduction of a new Public Health Act in one state was seen as providing the impetus "for councils to say, "we want to implement healthy design principles into our neighbourhoods'" [CH2]. Although the supportiveness of each state's legislative framework varied and did not guarantee successful project implementation in any state, such policies were noted to formalise the consideration of community health by LG [CH1, BE3], and were selectively referred to by advocates to instigate projects and secure internal LG funding [BE7]. A supportive state legislative setting was also noted to have the potential to encourage positive changes to LG policy around healthy planning [BE8, BE9]. Such policies were particularly noted to be enabling where they encouraged state government partnerships with LGs, such as through funding or resource provision [CH4], and where LGs otherwise would not have had the internal capacity or resourcing to undertake such projects [BE10].

Despite the identification of a supportive state framework as an enabler, LG's role in implementing state policies was important, whereby "as much as everyone goes 'oh, but it's policy', we all know that that doesn't necessarily happen at all. It has to be driven, and guided by those local areas" [CH5]. For instance, even in a setting where both planning and health legislation at the state level had recently changed to better support healthy planning, the ultimate effect of these changes would depend on "how those policies are implemented, how that filters down into action" [CH2]. Related to this consideration, a commonly identified barrier was that state policies were often discretionary [BE11] and lacked specificity [BE1, BE6], especially with regards to implementation. State policy was also noted to provide a strategic direction only, without a legislative mandate for action by LG [BE4]. Such a theme was typified by the perspective that "if [the state government says] 'we want to go this way', and then leave it all up to LG, it is really hard. It's good to have a bit of a stick, it's good to have some legislation" [CH6]. This mandate was generally missing though; even where best practice in healthy planning was present in the state policy setting, such policies had "no power or anything ... , it's a 'nice thing to do, if you can. And if you can't, we won't worry about it!'" [CH5].

A commonly identified enabler in response was the need "to find some legislative teeth at the state level, to get it going, to make sure that there's outcomes and outputs" [BE2]; [BE6, BE4, CH7]. Such policy at the state level could "require [healthy planning guidance] to get sourced, all those pools of information would then be tapped, formally, and in a systematic process" [BE8]. The complexity and "messiness" of addressing community health through changes to the built environment was nevertheless noted [BE1]. This leads to difficulties in creating effective top-down policy, and could be a reason that such "planning policies are written to have a bit of wriggle room" [BE11] with regard to implementation.

\subsubsection{State/LG Policies-General Role of LG}

State-level policies also influenced the role and function of LG more generally, which was identified as impacting on the ability for LG to consider and engage in healthy planning. An example of this was project financing, including the ability for LG to receive "recurring funding" through levies and rates [BE8]. Additionally, state policies ensured that LGs engaged in community consultation, which advocates identified as a "mechanism ... to start to bring in the health stuff, so that it can filter down through all of the various different and diverse components of what council does" [CH8]. However, as noted in Section 3.1.1, the states' legislative standing allowed them to "interfere" [BE3] in LG efforts in healthy planning. Advocates noted that LG decisions based on healthy planning considerations could be overturned at the state level:

LG provisions that are in planning policies quite often get challenged successfully by applicants at the state level, so for us, things that are probably legislation and code we find can be implemented more effectively [BE8]. 


\subsubsection{LG Policies-Planning and Health}

While a top-down mandate for healthy planning was identified as a potential enabler, the internal LG policy setting also impacted project uptake or failure. For instance, prior to it adopting a public health plan, one LG was noted as having "no talk between, you know, planning and design teams and community teams or the health teams" [CH4]. Meanwhile, the adoption of a public health plan facilitated such communication, increasing the likelihood of healthy planning initiative uptake [CH4]. It is particularly noted that the LG was not mandated to have a public health plan by the state government at the time of its implementation.

Further, the LG policy setting could be used to gain support for initiative implementation from those in senior roles, whereby "the Public Health Plan is a tool that you can kind of say, 'we have this that states that you must undertake these actions'. And if elected council members don't like it, you can say 'you approved this plan, don't forget'" [CH4]. However, where a LG policy setting was particularly supportive, this was generally due to the advocacy of an individual or group, as typified by the following response: "I was able to win over a lot of issues when I got the basic policy statement for footpaths in the strategy, I now had a clear policy statement" ([BE7] emphasis added). Also contributing to the ad hoc LG policy setting as a barrier was politicised policy decision-making, where "councillors ... make the final decisions on the policy ... They are two tasks in a way, that you might be able to get the staff on board, but you can't necessarily get the councillors on board" [BE12] (refer also to Section 3.2.1). A disparity between the regulatory or statutory setting of a LG and its strategic direction was also noted as a potential barrier, such as where:

some of the engineers still have, you know, things like road design guidelines, they can impede walkability ... and I suspect a lot of those manuals are still in place. But in terms of strategic planning, I would hope that there's nothing that we have current, as in adopted policy, that would impede healthy living and active travel [BE8].

The above presents a complex picture of the role of the policy setting as both a barrier to and enabler of healthy planning and active living initiatives. Even where relevant policies at the state and LG levels were evident, they were insufficient alone to ensure project implementation. Healthy planning policy at the LG level was largely open to ad hoc interpretation regarding initiative implementation, and often relied on individual efforts for its uptake. However, advocates generally considered that the lack of a supportive policy setting could be overcome through individual efforts or special interest groups. Conversely, a supportive state and LG policy environment alone was insufficient to ensuring initiative uptake and success. When questioned on the role of policies as barriers and/or enablers, respondents generally paid greater attention to political or other considerations, such as identifying that "the policy frameworks are ... there, it usually boils down to money, insurance, and other competing issues" [BE13]. Respondents considered barriers and enablers to initiative implementation to stem from "organisational structure as much as policy. And having a champion within the council who can just be there constantly" [BE11].

\subsubsection{Data, Evidence, and Guidelines}

Central to the re-emergence of a healthy planning paradigm has been a concerted effort to build and share the evidence base regarding the complex relationships between the built environment and health, as well as intervention efficacy. Respondents identified two primary types of information as enablers: research (i.e., studies undertaken as part of initiatives and/or academic studies) and guidelines. Existing research was noted to provide suitable evidence supporting the relationship between built environments and community health (relating also to the problem stream, such as whether NCD rates are even considered to be of concern to built environment professions), as well as the effectiveness of healthy planning and active living initiatives. An "explosion" of evidence was noted [BE3], particularly over the last 10 years and supporting the uptake of projects [CH1]. Advocates in this space were seen to play the role of a knowledge broker [71], sharing information and translating 
academic findings for practical use by practitioners [BE6]. However, while knowledge brokers can also "ensure that researchers are aware of issues confronting policymakers and practitioners" [71] (p. 236), this reverse flow of influence over research agendas was less commonly identified by respondents. LG requirements for localised evidence, and the difficulty of obtaining such requirements, were also identified as barriers, as typified by the following response whereby LGs:

want data, and that of course is always a tricky one to get, 'cause we don't have often the data they need down at local government area level ... where it's not that easy to have that research [CH5].

Concerns also existed around applying the international evidence base locally, and particularly that while such findings had applicability in Australia, such evidence was not informing policy [BE3]. Project implementation was noted as an enabler in this regard, offering an opportunity for the local evidence base to be strengthened. Initiatives were considered particularly valuable in providing quantitative data that justified implementation and could support subsequent projects [CH3], with the value of pilot or example projects in informing more qualitative aspects of project successes also noted [BE13].

The second type of information that acted as an enabler to initiatives was guidelines. Such guidelines generally related to evidence translation and project implementation, and were commonly produced by advocacy groups $[56,91,92]$. Similar to academic data and evidence, a suitable amount of guidance to support practitioners in implementing healthy planning and active living initiatives was considered to be available to Australian practitioners [BE3, BE5, CH6, CH7]. Instead, a barrier was how this research and guidance were implemented "on the ground" [BE12], with the challenge being to interpret and disperse the "truckload of guidelines and evidence" that was available [BE5]. More important than new evidence regarding the causal linkages between the built environment and community health was research into the development of "protocols and processes for ... integrating health into council planning" [CH8].

A setting of an incomplete and at times incongruent "legislative scaffolding" [BE5], including conflicts between policies at various levels of government and also internal to LG (such as between strategic and statutory), acted as a barrier to potential initiatives, as did concerns regarding a lack of evidence of project effectiveness, especially locally. The need to engage in political discourse to improve this policy setting was commonly recognised. As a result, the success or failure of projects was considered to more likely hinge on prevailing politics and a healthy planning paradigm, as explored below.

\subsection{Politics}

Given the relative policy void mandating project implementation at the LG level, motivators behind healthy planning decisions gain added importance. Various politically viable aspects of healthy planning were identified; however, the incomplete legislative setting led to policy changes and initiative implementation undertaken in a largely ad hoc manner rather than via an evidence-based decision-making process. This section identifies the various political considerations that acted as barriers to or enablers of healthy planning and active living project implementation. Such considerations include politicised decision-making processes, the notion that healthy planning is politically attractive yet that its implementation might be less so, the need to engage in partnerships as a response to this politicised setting, and the difficulties caused by short-term political cycles and thinking.

\subsubsection{Politicised Decision-Making}

As discussed above, the lack of a strong policy framework to support healthy planning led to a reliance on ad hoc, politicised decision-making. Such decisions were noted to play a significant role in policy uptake as well as project implementation. Respondents were aware of the opportunities this 
afforded, with one built environment advocate noting that health advocates were becoming "more educated about planning, and so ... they've got a better grasp on where those opportunities are to make interventions", such as a redirected focus "upstream" from opposing individual developments to influencing policy and offering guidance [BE11]. If the above policy setting were to be improved, the need to gain political support was commonly recognised, as typified by the following:

I think that establishing health-promoting policy probably starts with some political will at the top ...., otherwise it's just not going to fall on the radar of people who really do influence the health of people through the built environment ... Maybe if you got the political commitment from the top ... you would get policies in place that give the local government planners the teeth to be able to do stuff [BE6].

Politically-driven decisions regarding healthy planning were commonly identified at the LG level (refer also to Section 3.1.3), where a reliance on politically elected councillors to make key healthy planning decisions was a recurring theme. This reliance could act as an enabler, such as where "having the trust of the councillors was a big thing, because they control everything that we do, pretty much" [BE10]. Alternatively, politicised decision-making at the state level could provide a barrier to the integrated delivery of health-promoting environments, whereby:

the political impediment to LG is that we can prepare plans, but then their chance of being supported and implemented is hit-and-miss ... So, it's a very hard environment to work in when currently ... a lot of the state public and private transport infrastructure decisions are not based on any adopted strategies, so they're entirely politically made, whereas the land-use plans are made predominantly by the local government and state government. But then they don't always speak to the transport decisions that are made [BE8].

This theme of politicised decision-making was reasserted by a common identification of policy entrepreneurs [72], or a reliance on individual champions to bring about change. For instance, one advocate expressed the perception that "you can say what you want at a LG level, but if you've got a person in the right place ... , then it's going to happen, regardless of how much evidence and grassroots support you've got" [CH9]. In another instance, a head of a state government planning department who could be seen to be a policy entrepreneur "was absolutely instrumental in saying, 'walking and cycling matter' ... So, he was really important because there was strong leadership at a state level, that was high profile" [CH1]. Nevertheless, overall, politicised decision-making was generally viewed as being unfavourable to healthy planning outcomes. Such processes meant that "decision makers are still able to find loopholes" to avoid creating provisions for health-promoting environments [BE3].

\subsubsection{Politically Viable-General Notions}

Although the politicised decision-making process was criticised by the majority of respondents, enabling considerations were identified that assisted project uptake and implementation. A common enabler was community (and market) demand, whereby "communities are demanding that they want to live in safe, healthy places that ... they're able to walk around in, feel safe in, enjoy nature" [BE5]. This demand for such initiatives meant that they were also likely to appeal to politicians, whereby "the politicians could see votes in it ... talking about community well-being and stuff like that" [BE4]. It was considered that healthy planning and active living initiatives "push all the buttons from a political perspective because they are a good news story ... and are very attractive for politicians or mayors or CEOs" [BE14].

\subsubsection{Politically Contentious-Detailed Implementation}

Despite healthy planning concepts being attractive to communities and politically possible for politicians, it was generally considered that they would only be viable if details of implementation 
were avoided. While it was generally considered that "everybody's happy enough to have health and well-being in policy ... because there's no real negative to putting it in", concerns were likely to arise "if we were to get deeper into the process, and developers were to say, 'oh hang on' ... then they might oppose that" [CH9]. This might be a contributing factor to the relative policy void and lack of legislative impetus for project implementation identified in Section 3.1. As a further example, the same advocate stated that healthy planning and active living initiatives were viable given that "health, I suppose, it doesn't threaten anyone ... is someone going to say they want to make a sick community? Of course not", while contrastingly outlining the existence of:

huge political barriers. I mean it's one thing to say you know, 'oh yeah, we'll have an objective about health.' Who's going to fund it? How are you then going to implement that? ... If it's in the case of a local council through the planning system, are they going to get more resourcing? Is a council that's really proactive in providing this sort of infrastructure for its community, are they going to get rewarded in some way? [BE5].

\subsubsection{The Need for Partnerships}

Partnership formation was considered to be an important enabler of projects in this politicised setting. Respondents noted various partnerships that assisted project uptake, with the most commonly identified being those between LG and an external partner (such as with a non-government organisation (NGO) or regional health service), vertically between government levels, interdepartmentally within a LG, and partnerships that existed externally to LG (including between state and regional actors, or with developers). Partnerships provided LG with guidance and support (including resourcing and funding) [CH3, BE2]. While policy that encouraged partnerships was noted as an enabler (refer to Section 3.1.1), in many instances, partnerships influenced the policy framework in which an LG was operating. This was typified in an example where the policy framework was:

ad hoc, because ... it relates to a large degree to how involved the local health district has been in relation to that particular local government area, as to how good a relationship we've had, in terms of input... So it's good where we have had that input [CH10].

Partnerships were found to assist project implementation, and also to result from such projects once they were implemented. This positive cycle was illustrated with regard to siloed LG functioning, whereby project implementation forced departmental collaboration, which improved integration across the LG [CH2]. Interdepartmental partnerships within LG were noted to have particular importance in project success, such as where:

you need people who can provide a technical response, and you need people who can be that community interface. So, we had a great partnership with engineering that ensured we were able to bring those different types of skills together for that community benefit [CH11].

All of the advocates acknowledged the value of partnerships within and external to LG, and many (whether they had roles within or external to LG) discussed a common strategy of engaging in partnerships with people in higher-level political and bureaucratic positions of LG in order to maximise success. The formation of partnerships was generally seen as a way for advocates to influence decision-makers within LG and encourage the increased implementation of healthy planning [CH8, CH12]. However, advocates external to LG saw their role in partnerships as being "helpful", whereby "it's always about that relationship, isn't it, in connecting LG in partnerships when they need things connected, or ... getting the right people to come" [CH5].

\subsubsection{Timeframes}

Different aspects of healthy planning were noted to be subject to different timeframes, which acted as a barrier to project uptake. The adoption of healthy planning processes and initiatives, and changes 
to the built environment were all noted as changes that occur in the medium to long-term [CH12]. Similarly, the benefits of healthy planning and active living initiatives generally presented themselves over a long timeframe [CH12, BE2]. However, such timeframes sit in contrast to short-term political cycles and plan creation [BE3], as discussed in Sections 3.2.1-3.2.3. The contrasting timeframes evident in this field are typified by the following statements:

there'll always be that political question of when an election is coming up in three, four years' time, of what can a party deliver now, that's going to make a difference, when we're taking about [a] 20,30, 40-year horizon for a new community, where people move in and they start to get those health benefits ... that is part of the research translation I guess, given that planning is so political [BE6].

it's politically difficult for governments ... because in three or four-year government cycles, they're trying to get re-elected, and so it's not politically feasible for them to plan strategically long-term, 'cause we're talking 10, 20, 30-year timeframes for getting the benefits of delivery. So that's ... the overarching problem in terms of healthcare delivery and health promotion and designing healthy urban streetscapes [CH7].

This notion of contrasting timeframes impacting on project consideration and implementation is related to the relatively weak policy setting (refer to Section 3.1) and the various relevant political considerations that then gain added significance. Such short-termism was a barrier to the widespread and effective implementation of health-supportive settings, presenting a need to move "beyond an election timeframe and shift beyond sort of personal interests of council workers and health workers and be more of a systemic thing" [CH8]. For instance, political "churn" at the state level [BE3] led one LG practitioner to note that:

every time you get a state government reshuffle it's like we brace ourselves, like, what's going to be the in-thing, what's going to be the new thing? Whereas the strategic plans get done over a 10, 20-year timeframe, so I think that's definitely a barrier to it [BE8].

The above section has examined politicised decision-making in healthy planning, with general concepts of such being considered politically attractive amongst advocates, politicians, and the community. However, concern was common amongst advocates and politicians that the actual implementation of initiatives would be less politically accepted. Partnership formation was identified as being a key enabler to project implementation and success, potentially as a result of the assistance that such partnerships might provide to LGs through resource provision or advocacy work in a politicised setting. Such a politicised setting led to a disparity between long-term built environment projects, changes to population health, and short-term political cycles. However, similar to the policy setting outlined above, while considerations that assisted or discouraged project uptake were identified, no distinct lists of prohibitive barriers and / or definitive enabling factors that ensured successful project uptake presented themselves. Instead, the above political considerations were influenced heavily by various factors relating to a prevailing healthy planning paradigm, as discussed below.

\subsection{Conveying the 'Problem' (or the Healthy Planning Paradigm)}

With this context in place, where a relative policy void plays a limited role in healthy planning implementation, and whereby politicised decisions can influence project uptake, important elements relating to the way the 'problem' of planning for health is conveyed (or elements that are indicative of a healthy planning paradigm) emerge as key barriers or enablers. Such a healthy planning paradigm can be seen as being promoted via discussions around co-benefits, through particular avenues of communication, and through 'problem' framing. These ideas are explored below. 


\subsubsection{Co-Benefits and "Health by Stealth"}

The healthy planning paradigm draws heavily on the promotion of projects through discussions and uses of benefits other than health to justify projects, which are often called co-benefits. Co-benefits can support healthy planning and active living initiatives, or alternatively, community health can be a co-benefit of an initiative with a separate focus [61]. While co-benefits were identified as enabling, the need to use co-benefits in supporting initiatives can be seen to stem from the limited policy impetus for healthy planning, as discussed in Section 3.1, whereby:

where things have actually had a health focus, LGs have had to use other means, like, you know, character of the neighbourhood or other things like environmental health factors, whereas the kind of public health factors have never been taken into account [CH2].

Specific healthy planning and active living initiatives identified by respondents were most commonly implemented due to their economic benefits and an associated marketability or political benefit (refer also to Section 3.2.2), with community health then considered to be a co-benefit of such projects. With regard to concepts that might encourage LG to consider healthy planning more often, one respondent stated that:

I'd like to say ... health should be actually really important from a planning perspective ... but in reality, I don't think that's going to make any difference. It's when it becomes either marketable or politically viable, that's how it's going to gain traction [BE1].

Health advocates in particular saw improved economic considerations as a "means to an end" through which to promote healthy planning to LG and encourage project uptake [BE11]. In a limited number of circumstances, improving community health was considered capable of being the primary driver of implementation, such as where:

climate change has somehow become a contentious political issue ... But what we find is the politicians and the community find it much harder to dismiss the evidence of health impacts ... if we can push a graph in front of a politician, and show that cities with a lot of walking and cycling have better cardiovascular health, those things are much harder to refute [BE8].

However, even where community health benefits were explicitly discussed by advocates, such benefits were generally expressed through the economic or lifestyle improvements resulting from them [BE7, BE9, BE14]. Advocates most commonly talked about the economic and (natural and built) environment benefits of what could otherwise be seen as healthy planning, in an approach that has been termed "health by stealth" [93-95]. Health by stealth employs co-benefits that have been identified as being politically viable (refer to Section 3.2.2) in order to promote projects, or uses terms that are considered more marketable and attractive than 'health', such as 'well-being' [BE4, BE11, CH9] or 'liveability' [CH11, BE11]. The concept of health by stealth is illustrated by the perspective that:

advocates shouldn't talk about healthy planning and disease prevention, we should just talk about good planning. Let's make good planning and planning standards improve; that incorporates this whole idea of health, or healthy urban environments [BE2].

Using notions of health by stealth was noted as an enabler to policy change and initiative uptake, where "even if policies don't explicitly mention the word health, but are tweaked towards, you know, designing new development, incorporating healthy design principles, I think that's important" [BE11]. Health by stealth relied heavily on the discussion of co-benefits, and was seen as a way for a common message amongst advocates to be developed. For instance, one respondent stated that in successfully advocating for such changes:

I don't think you'd talk about health. I think in the current climate you'd talk about the economic value of creating connected environments ... you'd just be speaking about the 
economic benefits of making those changes, and knowing that they will deliver big health benefits as well. So really, you're asking for exactly the same thing, but you're just speaking their language [BE6].

Healthy planning and active living initiatives are more commonly initiated due to reasons other than the improvement of community health. While the use of co-benefits was considered to be an enabler to project implementation, this reliance on health by stealth might be the result of either the limited policy impetus for healthy planning, or of potential difficulties in the measurement and communication of healthy planning benefits, particularly locally (refer to Section 3.1.4).

\subsubsection{Communication}

In addition to the co-benefits considered above, the importance of communication was also noted in the implementation of healthy planning initiatives, and was considered central to advocates' efforts, which necessitated a "distillation of the evidence into a message, sound bite, or policy ask" [CH13]. Three common flows of communication were identified as being central to the healthy planning paradigm and as enablers of project uptake. The most frequently identified flow of communication was from LG to the community (i.e., engaging in community consultation, or more commonly communicating the benefits of an initiative), with advocates commonly acknowledging the important role of LG "in engaging with their community, educating citizens, involving people in deliberative discussion ... to actually foster informed, meaningful and assertive civic involvement and decision-making" [BE3]. Communication between NGOs and LG was the second most commonly identified form, and generally included NGOs advocating for changes in the policy framework or built setting [CH1, $\mathrm{CH} 2, \mathrm{CH} 13]$, or engaging in skill development or the dissemination of research to LG practitioners [BE6, BE2]. Communication from regional actors to LG was also central to the promotion of a healthy planning paradigm [CH5, $\mathrm{CH}$, $\mathrm{CH} 10]$, with a similar role identified between regional actors and NGOs. Such communication was important to inform the community of the central role that LG can play in this healthy planning space [BE3, BE4, BE12]. However, health advocates also identified a need to (re-)establish health's role in planning in the perspective of LG practitioners, with a key message being that healthy planning is:

not building hospitals, necessarily. It's [the] whole environment, and planning ... and that's often been quite eye-opening for councils who haven't really seen the health profession's role in that sphere before [CH10].

Communication from NGOs particularly was identified as an enabler, with such organisations having the ability to communicate "information that governments probably don't want to hear", particularly as "state governments or federal governments would not necessarily produce reports that have such open and frank statements in them" [BE10]. Less commonly identified avenues of communication that benefited healthy planning and active living initiatives included from one LG to another, and from academia to built environment professionals.

\subsubsection{Framing}

Similar to the theme of communication was the need to frame healthy planning in a certain way in order for projects to be considered and implemented. Key themes that emerged with regard to framing were the need to align a common message amongst advocates, tensions over whether healthy planning was framed as good planning or an extra add-on to be considered (and whether it was even necessary to mention health and health outcomes in advocating for such changes), and the need to alter advocacy messages to align with different LGs.

Aligning a single message or idea amongst advocacy groups or when implementing an initiative was considered to assist project uptake, such as the need for advocates to "sing from the same songbook" [CH13], "come together and support LG with a consistent message" [CH2], and to "go with one voice to local government ... it's not a good look, us all going separately" [CH5]. Such a 
concern was generally limited to advocates in the community health professions aiming to influence built environment practice, though some built environment advocates did note such an approach as an enabling factor [BE5, BE6]. An aligned message would relate to "consistency ... about what health's role is and really sort of cementing it as a critical function" in the built environment profession [CH8].

Related to the above consideration, a barrier to healthy planning and active living initiatives was that they were commonly framed as being additional considerations to those issues that were central to planning, and involving extra, "expensive infrastructure like shared pathways and stuff like that, so ... there's sort of those attitudes and the funding is always a problem" [BE5]. When framed in this way, projects became less politically viable. However, an alternative approach was for community health "to be more clearly defined as a planning issue ... as it once was when the profession started" [BE6]. It was a commonly held perspective amongst advocates that "healthy urban design principles are ... good planning principles, you know, they're not outside the realms of what planners do or think" [BE2]. If a healthy planning initiative could be framed as such, as "part-and-parcel of all the other work that councils do, then it doesn't necessarily have to be an onerous add-on, it can be a co-benefit" [BE5], with a health advocate noting that built environment practitioners often respond with "we already do that" when presented with healthy planning guidance [CH8]. In contrast, some advocates considered that it was not necessary for concepts of 'community health' to be made explicit in order for projects to succeed, and that instead, the discussion of co-benefits and the use of health by stealth (refer to Section 3.3.1) were sufficient to support healthy planning and active living initiatives.

Yet whether it was through health by stealth or framing health as a central consideration to planning, the need to align advocacy to the built environment professions and each individual LG was noted, particularly by advocates in community health roles. Such an approach could help to avoid what one advocate termed "health imperialism", whereby the "health profession asks "how are you going to help me in this way?' rather than 'how can we help each other?'" [CH13]. Avoiding such a barrier could be achieved by advocates better responding to the needs and aspirations of a LG. As an example, where a LG did not see the promotion of community health as their responsibility, initiatives were instead framed around "community well-being or having a livable environment and community happiness" which "they do see ... as being a bit more of their realm" [BE11], indicating that health by stealth could also be applied to LG.

Providing a common message amongst advocates to LG and tailoring this message to each LG's context and needs were identified as enabling factors to project implementation. Yet, there was less agreement amongst advocates as to whether community health should sit centrally to and drive planning practice, or exist in the background, such as being a co-benefit of economically-driven projects.

\section{Discussion}

The above section presents a complex and interrelated set of factors that play varying roles in supporting or discouraging the uptake and success of healthy planning and active living initiatives. This section compares these findings against the existing literature, and briefly touches on the structural barriers to healthy planning that these findings present.

The healthy planning policy setting identified by advocates sits in stark contrast to the "strong regulatory environment" introduced in Australia in response to community health issues such as smoking, road injuries, communicative disease epidemics [63], and crime [96]. Such a legislative setting has the potential to instigate "long-term cultural and attitudinal changes towards health promoting behaviours", and achieving a sustainable built environment is "impossible when simply relying on ad hoc citizen initiatives without a clear structural future vision" [97] (p. 10). The state level in Australia gains particular importance in this regard, given that state legislation and funding influence LG agendas and policies [63]. However, although positive changes to the health and planning policy settings were identified, particularly recently, the existing setting in Australia was not considered to provide a sufficient mandate for LG to engage in healthy planning. 
Findings relating to the policy setting at the LG level are consistent with, and are also influenced by, previously identified barriers to healthy planning at the state level. These barriers include inconsistencies in the legislative setting, a disconnect between state budgets and plans, and a lack of impetus for healthy planning locally, with a focus on strategic direction and aspirations at the expense of detailed implementation [14,47]. Advocates generally considered LG to be hamstrung by the role of state government providing little supporting legislation or detailed impetus for project implementation, and with LG efforts to engage in healthy planning able to be overturned at the state level. A more supportive top-down legislative setting at the state level, or greater devolution of planning powers and responsibilities from states to LG, were two identified routes by which these structural barriers might be overcome. However, the perception that efforts of individual or special interest groups could overcome such policy barriers reflects overseas findings regarding local health promotion, whereby "local health policy did not appear to be of pivotal importance to the operations of stakeholders or their organisation" [76] (p. 117). The policy setting, while it can support or hinder projects, neither acts as a prohibitive barrier or definitive enabler to project implementation. For instance, advocates in South Australia, where a relatively supportive legislative setting is evident (Note 2 in Appendix A), identified the same barriers to implementation as advocates in states with less supportive settings.

The reliance on politicised decision-making and partnership formation is both symptomatic of and contributes to this ad hoc policy setting. With regard to politics, the findings reflect the limited evidence-based decision-making resulting in ad hoc decisions that are based instead on community opinion, which is a noted barrier to undertaking healthy planning [63]. This absence of evidence-based decisions instead places importance on individual champions, with reactive decision-making based more on political popularity than community health benefits [76] (p. 117). The interviewed advocates identified general concepts of health as being politically viable and as a "non-threatening good news story", and the avoidance of detailed implementation of healthy planning in policy has been noted as "an explicit strategy" at a state level [47] (pp. 8, 10). However, the avoidance of detailed implementation presents barriers across multiple levels. Firstly, it represents a perceived unwillingness of the community to accept such changes, with broader concepts of health being "innocuous" [47] (p. 9). However, the emerging evidence base presents the community [98] and businesses [99] as receptive to such changes. Secondly, concerns that healthy planning will be contentious among the community might prevent policies from including details of implementation, which is another identified barrier. Such perceptions are closely tied to the way that these initiatives have been framed (refer to Section 3.3.3), and perhaps go some way towards explaining the generally unsupportive state legislative settings (refer to Section 3.1.1). This also supports policy findings at the LG level, whereby a "lack of willingness to define goals and targets" can lead to actions "framed in very general, fragmented and intangible ways" [100] (p. 409).

Partnerships were noted to be essential in bridging horizontal and vertical silos [64,71,101], as well as providing funding and resourcing opportunities. This research also finds partnerships to be a response to the policy void, whereby politicised decisions are supported through advocacy efforts of partners to, or on behalf of, LG.

The examination of the problem setting, or the notion of a healthy planning paradigm, brings forth various tensions within the field, such as the contested nature of built environment governance [41] as well as "definitional tensions" and variations in approaches to framing healthy planning [39] (p. 3). While existing evidence and data were accepted to be sufficient, the difficulty in gaining data that supported specific initiatives, particularly at a local level, was noted as a barrier. In response to this barrier, the healthy planning paradigm gained increased importance. As part of this paradigm, co-benefits were typically mentioned or used by respondents as a way to communicate the value of such initiatives and measures. The use of co-benefits in healthy planning can reduce siloed operation and add benefits to economic calculations of project efficacy [102] (p. 125). Using co-benefits to support projects that benefit community health has a long history [103] (p. 43). However, rather than just adding value when healthy planning and active living initiatives are considered, the use of 
co-benefits can also be seen as a response to the difficulty of establishing the evidence base to support projects [41]. This is particularly true at the local level, given that the resulting health benefits are subject to such multifaceted and complex factors [104,105]. The use of co-benefits can also be seen as efforts to position projects in areas where there is a stronger policy mandate (such as economics or environmental management), or as a response to dealing with extended timeframes for health benefits to be realised (refer to Section 3.2.5). The paradigm of healthy planning relies heavily on concepts of co-benefits, which although acting as short-term enablers, present more structural barriers to the widespread adoption of healthy planning. For instance, the use of co-benefits is not needed when justifying the consideration of other planning issues, such as crime prevention through environmental design (CPTED) in Australia [96].

Given its interdisciplinary nature, communication in the healthy planning field is important [41] and can promote collaboration [64]. The communication of project benefits to the community is also an important consideration in gaining support for projects [41]. Of the three most common flows of communication identified by advocates-LG to the community, regional operators to LG, and NGO to LG-two involved communication from predominantly health organisations (at both the regional level and in NGO advocacy roles) to LG. This finding supports the identified importance of communication and cooperation between the health and built environment disciplines [42,106], particularly from the health to the built environment professions. Communication between academia to built environment professionals was also identified as having less importance than the above-mentioned flows of communication, reaffirming the need for academic guidance to be successfully interpreted [71] and disseminated [67].

The adoption and acceptance of community health as a planning issue has been slow [28,106], and so, the way that healthy planning has been framed was identified as a particularly important consideration. The use of framing techniques has been noted in agenda setting for healthy planning at the state level in Australia [107]. Findings indicate that initiatives can be framed as being central to planning, or as "requiring extra work or extra funding", in which case they come to be viewed as being "optional" and are less likely to be considered for project uptake [57] (p. 102). Alternatively, some advocates preferred to focus on co-benefits through "health by stealth", whereby "even if 'health' is not an explicit policy goal, integrated policies can have significant health co-benefits by addressing social determinants of health" [14]. The use of health by stealth concepts have been identified in the promotion of healthy food strategies, and also in some built environment $[93,94]$ and behaviour change [95] settings. This has strong links to the use of other (co-)benefits for implementation, whereby health improvement is an implicit benefit rather than an explicit project motivator [94]. While this approach might have occurred in the past [108] and is considered sufficient for planning to implicitly support community health at a state level [14], the use of such a concept reinforces the largely inadequate policy setting and advocate concerns that the implementation of healthy planning is unlikely to be politically supported. Practically, understandings of co-benefits and discussions around such could be deepened through greater consideration of indigenous perspectives on the complex relationship between ecosystems and health, in contrast to contemporary western understandings [109]. Such perspectives are commonly excluded from western scientific thinking and particularly planning $[110,111]$. However, where these perspectives have been recognised, such as through the field of ecohealth $[8,109,112]$ or in specific projects, including in health assessment in New Zealand [113] or land-use planning in Canada [114], they have had success. Such an approach might be a way to more holistically and effectively analyse and discuss healthy planning and active living efforts.

With regard to supporting project uptake, the existing academic evidence base was considered to have less value for LG than local evidence, whereby "local government needs practical, relevant data at the local government level" [63] (n.p.), particularly regarding examples of successful interventions [62]. Cost-benefit analyses and cases of decision-making that demonstrated project effectiveness and enabled implementation were deemed beneficial $[23,115]$, as were evaluations that considered social, 
environmental and economic benefits, reflecting the use of co-benefits and providing an alternative to more difficult "evidence of true causality" between community health and the built environment [41] (p. 59). The importance of communicating this knowledge to practitioners through methods such as advocacy and research translation [71], and the need to undertake more evaluations of locally implemented projects [63], were identified as potential enablers.

The concept of time is an important public health consideration [104], and is especially relevant to "attempts to create healthy local communities based on local government areas" [100] (p. 403). The multifaceted and contested nature of planning means that both policy and built environment changes generally take an extended amount of time [14,116], while the nature of socio-ecological processes means that (health) impacts are not immediately identifiable [105]. This can create tensions in seeking "strategies that provide a balance between achieving long-term goals and the immediate results" [100] (p. 403). The contrast between these long-term considerations and shorter-term political cycles creates difficulty in relation to developing the evidence base and promoting projects using community health benefits; thus, it is another potential reason behind projects' reliance on a healthy planning paradigm. In response to this issue of varied timeframes, practitioners and advocates must "work with time as a component of [the] decision-making process" [117] (p. 37).

An important aspect of healthy urban planning that did not appear through the interviews is the lack of institutional engagement with indigenous and other culturally-specific values. Although the methodology used allowed for the participants to state any indigenous perspectives or issues linked specifically to indigenous worldviews and values, none of them did so. The failure of the respondents to refer to indigenous issues or other culturally-specific values is representative of the embedded institutional racism invisible to those in positions of power.

\section{Limitations and Future Research Directions}

It is hoped that this research will be relevant to advocates and practitioners operating within LG or encouraging healthy planning at the LG level. Although an Australian context is examined, and caution should be taken in applying these findings to different settings, the emergent themes are considered broad enough to have relevance to similar institutional contexts, or to those places attempting to address similar issues. Studies in other global contexts and cultures might be valuable in allowing comparisons between settings, particularly as localised research is important in guiding decision-making [23]. While considerations around participation in and the organisation of such initiatives by indigenous and culturally diverse people were not specifically targeted in this study, they too might also provide beneficial channels of exploration. Given that indigenous thinking has contributed substantially to understandings on planetary and human health, as well as their links, the greater examination of such perspectives in future investigations, or the inclusion of indigenous people in organising or participating in future initiatives, is also likely to hold value [111].

Additionally, future studies might build on this research by further investigating the structural barriers to more evidence-based, consistent, and equitable implementation of healthy planning. Greater academic attention might also be afforded the flow-on impacts of project implementation, while the tensions between the ideas of health by stealth, co-benefits, and the framing of health as a planning issue could also be further examined.

\section{Conclusions}

The study outlined barriers to and enablers of initiative uptake in healthy planning. This research's findings point to an inconsistent legislative setting, politicised decisions privileged at the expense of evidence-based decision-making, and healthy planning initiatives that rely on a particular paradigm for success. In turn, this incomplete and at times inconsistent setting provides opportunities for policy entrepreneurs to create policy windows, or opportunities to bring about change [72]. The identification of various barriers and enablers will offer practical guidance to those practitioners or advocates undertaking initiatives at the LG level. However, an (over)reliance on policy entrepreneurs such as 
individual advocates and champions $[63,67]$ is unlikely to produce the equitable spatial delivery of health-promoting environments across LGs, or across individual LGs. Simultaneously, and perhaps paradoxically, those policy entrepreneurs are most likely the best able to produce more sustainable and long-lasting change.

The findings indicate that the policy setting can be changed to support healthy built environments, but that policy interpretation and project implementation on the ground mean that even supportive state and LG policy settings are not sufficient alone to guarantee project uptake and success. Nevertheless, supportive state and LG policy settings did assist projects, and improvement of the legislative setting, particularly at the state level to provide a clear mandate for policy and action, is an important step to delivering more widespread and equitable healthy environments. Given the contributions that policies, politics, and paradigm shifts can make towards planetary health, the role of LG needs to be strengthened and properly supported. LG in Australia is critically positioned to provide built environment initiatives responding to increasing NCD prevalence, climate change, and various other planetary health considerations.

As it stands at the moment, healthy planning is considered to be an attractive notion politically, but politicised decision-making and an avoidance of details lead to a reliance on individual advocates or champions to progress initiatives. Such ad hoc decision-making increases the importance of the healthy planning paradigm, particularly in regard to the ways that healthy planning and the issue of NCDs are framed and communicated. With the built environment providing a most needed setting for actions towards planetary health, the identified factors indicate potential reasons for the relatively slow delivery of health-promoting and sustainable urban forms in Australia.

Acknowledgments: This work was supported by the Australian Postgraduate Award (APA) and Curtin Research Scholarship (APA-CRS). The third author thanks the Australian Research Council for financial support. We also acknowledge the help of the two anonymous referees and the Journal's Editor which improved the quality of the paper.

Author Contributions: Anthony McCosker, Anne Matan and Dora Marinova conceived and designed the experiments; Anthony McCosker performed the experiments; Anthony McCosker analysed the data; Anthony McCosker, Anne Matan and Dora Marinova wrote the paper.

Conflicts of Interest: The authors declare no conflict of interest.

\section{Appendix A}

Note 1. The social determinants of health are those 'socio-economic conditions that influence the health of individuals, communities and jurisdictions as a whole. These determinants also establish the extent to which a person possesses the physical, social and personal resources to identify and achieve personal aspirations, satisfy needs and cope with the environment' [118], also [62,119,120].

Note 2. The South Australian state legislative framework includes the South Australian Public Health Act 2011 [121] which places a mandate on LG to proactively plan for community health in a regional public health plan (s. 51), and the Planning, Development and Infrastructure Act 2016 [122], which notes planning, design and development 'to support active and healthy lifestyles and to cater for a diverse range of cultural and social activities' as a planning principal (part 2, division 1, s. 14).

\section{References}

1. Girardet, H. Healthy cities, healthy planet: Towards the regenerative city. In The Routledge Handbook of Planning for Health and Well-Being: Shaping a Sustainable and Healthy Future; Barton, H., Thompson, S., Burgess, S., Grant, M., Eds.; Routledge: New York, NY, USA, 2015; pp. 61-73. ISBN 978-1-13802-330-7.

2. Horton, R.; Lo, S. Planetary health: A new science for exceptional action. Lancet 2017, 386, 1921-1922. [CrossRef]

3. Horton, R.; Beaglehole, R.; Bonita, R.; Raeburn, J.; McKee, M.; Wall, S. From public to planetary health: A manifesto. Lancet 2014, 383, 847. [CrossRef] 
4. Whitmee, S.; Haines, A.; Beyrer, C.; Boltz, F.; Capon, A.G.; de Souza Dias, B.F.; Ezeh, A.; Frumkin, H.; Gong, P.; Head, P.; et al. Safeguarding human health in the Anthropocene epoch: Report of the Rockefeller Foundation-Lancet Commission on planetary health. Lancet 2015, 386, 1973-2028. [CrossRef]

5. The Lancet Planetary Health. Welcome to The Lancet Planetary Health. Lancet Planetary Health 2017,1 , e1. [CrossRef]

6. Porter, E. Postcolonial consequences and new meanings. In The Routledge Handbook of Planning Theory; Gunder, M., Madanipour, A., Watson, V., Eds.; Taylor and Francis: New York, NY, USA, 2018; pp. 167-179. ISBN 978-1-13890-501-6.

7. Kingsley, J.; Patrick, R.; Horwitz, P.; Parkes, M.; Jenkins, A.; Massy, C.; Henderson-Wilson, C.; Arabena, K. Exploring ecosystems and health by shifting to a regional focus: Perspectives from the Oceania EcoHealth Chapter. Int. J. Environ. Res. Public Health 2015, 12, 12706-12722. [CrossRef] [PubMed]

8. Saint-Charles, J.; Webb, J.; Sanchez, A.; Mallee, H.; Wendel de Joode, B.; Nguyen-Viet, H. Ecohealth as a field: Looking forward. EcoHealth 2014, 11, 300-307. [CrossRef] [PubMed]

9. Liddle, B. Urbanization and inequality/poverty. Urban Sci. 2017, 1, 35-41. [CrossRef]

10. Newman, P.; Kosonen, L.; Kenworthy, J. Theory of urban fabrics: Planning the walking, transit/public transport and automobile/motor car cities for reduced car dependency. Town Plan. Rev. 2016, 87, 429-458. [CrossRef]

11. Newman, P.; Kenworthy, J. The End of Automobile Dependence: How Cities Are Moving beyond Car-Based Planning; Island Press: Washington, DC, USA, 2015; ISBN 978-1-61091-4-628.

12. Smith, M.; Hosking, J.; Woodward, A.; Witten, K.; MacMillan, A.; Field, A.; Baas, P.; Mackie, H. Systematic literature review of built environment effects on physical activity and active transport-An update and new findings on health equity. Int. J. Behav. Nutr. Phys. Act. 2017, 14, 1-27. [CrossRef] [PubMed]

13. Matan, A.; Newman, P. Active transport, urban form and human health: Developing the links. In Proceedings of the 7th Making Cities Liveable Conference, Kingscliff, Australia, 9-11 July 2014.

14. Lowe, M.; Whitzman, C.; Giles-Corti, B. Health-promoting spatial planning: Approaches for strengthening urban policy integration. Plan. Theory Pract. 2017, 1-18. [CrossRef]

15. Kellett, J. Australian cities and climate change. Built Environ. 2016, 42, 145-157. [CrossRef]

16. Demaio, A.R.; Rockström, J. Human and planetary health: Towards a common language. Lancet 2015, 386, e36-e37. [CrossRef]

17. Grecequet, M.; DeWaard, J.; Hellmann, J.J.; Abel, G.J. Climate vulnerability and human migration in global perspective. Sustainability 2017, 9, 720. [CrossRef]

18. Giles-Corti, B.; Vernez-Moudon, A.; Reis, R.; Turrell, G.; Dannenberg, A.L.; Badland, H.; Foster, S.; Lowe, M.; Sallis, J.F.; Stevenson, M.; et al. City planning and population health: A global challenge. Lancet 2016, 388, 2912-2924. [CrossRef]

19. Ge, Y.; Dou, W.; Liu, N. Planning resilient and sustainable cities: Identifying and targeting social vulnerability to climate change. Sustainability 2017, 9, 1394. [CrossRef]

20. United Nations. Sixty Seventh Session Political Declaration of the High-Level Meeting of the General Assembly on the Prevention and Control of Non-Communicable Diseases; United Nations: New York, NY, USA, 2011.

21. Jiang, Y.; Hou, L.; Shi, T.; Gui, Q. A review of urban planning research for climate change. Sustainability 2017, 9, 2224. [CrossRef]

22. Newman, P.; Matan, A. Human mobility and human health. Curr. Opin. Environ. Sustain. 2012, 4, 420-426. [CrossRef]

23. Sallis, J.F.; Bull, F.; Burdett, R.; Frank, L.D.; Griffiths, P.; Giles-Corti, B.; Stevenson, M. Use of science to guide city planning policy and practice: How to achieve healthy and sustainable future cities. Lancet 2016, 388, 2936-2947. [CrossRef]

24. Watts, N.; Adger, W.N.; Agnolucci, P.; Blackstock, A.; Byass, P.; Cai, W.J.; Chaytor, S.; Colbourn, T.; Collins, M.; Cooper, A.; et al. Health and climate change: Policy responses to protect public health. Lancet 2015, 386, 1861-1914. [CrossRef]

25. Burton, A.; Bambrick, H.; Friel, S. If you don't know how can you plan? Considering the health impacts of climate change in urban planning in Australia. Urban Clim. 2015, 12, 104-118. [CrossRef]

26. Levy, B.S.; Patz, J.A. Climate change, human rights, and social justice. Ann. Glob. Health 2015, 81, 310-322. [CrossRef] [PubMed] 
27. Prüss-Ustün, A.; Wolf, J.; Corvalán, C.; Bos, R.; Neira, M. Preventing Disease through Healthy Environments: A Global Assessment of the Burden of Disease from Environmental Risks; World Health Organisation: Paris, France, 2016.

28. Lawrence, R.J. Mind the gap: Bridging the divide between knowledge, policy and practice. In The Routledge Handbook of Planning for Health and Well-Being: Shaping a Sustainable and Healthy Future; Barton, H., Thompson, S., Burgess, S., Grant, M., Eds.; Routledge: New York, NY, USA, 2015; ISBN 978-1-13802-330-7.

29. Joh, K.; Chakrabarti, S.; Boarnet, M.G.; Woo, A. The walking renaissance: A longitudinal analysis of walking travel in the greater Los Angeles area, USA. Sustainability 2015, 7, 8985. [CrossRef]

30. Stevenson, M.; Thompson, J.; de Sá, T.H.; Ewing, R.; Mohan, D.; McClure, R.; Roberts, I.; Tiwari, G.; Giles-Corti, B.; Sun, X.; et al. Land use, transport, and population health: Estimating the health benefits of compact cities. Lancet 2016, 388, 2925-2935. [CrossRef]

31. Hooper, P.; Giles-Corti, B.; Knuiman, M. Evaluating the implementation and active living impacts of a state government planning policy designed to create walkable neighborhoods in Perth, Western Australia. Am. J. Health Promot. 2014, 28, S5-S18. [CrossRef] [PubMed]

32. Kent, B.; Ampt, E. Why 'building it' doesn't always mean they will come: Understanding reactions to behaviour change measures. In Proceedings of the Australasian Transport Research Forum, Perth, Australia, 26-29 September 2012.

33. Department of Transport. Your Move Programs. Available online: https://www.transport.wa.gov.au/ activetransport/your-move.asp (accessed on 21 December 2017).

34. Foulkes, C. Lessons from Healthy Together Geelong: Delivering systems change at scale across two levels of government. Obes. Res. Clin. Pract. 2014, 8, 33. [CrossRef]

35. Foulkes, C. Systems interventions to halt and reverse rising trends in obesity what theories, methodologies and methods actually aid practice: Cases from Healthy Together Geelong. Obes. Res. Clin. Pract. 2014, 8, 33-34. [CrossRef]

36. Weichselbaum, E.; Hooper, B.; Buttriss, J.; Theobald, C.; Sgarabottolo, V.; Combris, P.; Strigler, F.; Oberritter, H.; Cullen, M.; Valero, T.; et al. Behaviour change initiatives to promote a healthy diet and physical activity in European countries. Nutr. Bull. 2013, 38, 85-99. [CrossRef]

37. Jackson, R.J.; Dannenberg, A.L.; Frumkin, H. Health and the built environment: 10 years after. Am. J. Public Health 2013, 103, 1542-1544. [CrossRef] [PubMed]

38. World Health Organisation. Global Status Report on Noncommunicable Diseases 2014; World Health Organisation: Geneva, Switzerland, 2014.

39. Harris, P.; Friel, S.; Wilson, A. 'Including health in systems responsible for urban planning': A realist policy analysis research programme. BMJ Open 2015, 5, 1-7. [CrossRef] [PubMed]

40. Kent, J.; Thompson, S. The three domains of urban planning for health and well-being. Plan. Lit. 2014, 29, 239-256. [CrossRef]

41. Kent, J.; Thompson, S.M.; Jalaludin, B. Healthy Built Environments: A Review of the Literature; Healthy Built Environments Program, City Futures Research Centre, UNSW: Sydney, Australia, 2011.

42. Paine, G.; Thompson, S. What is a healthy sustainable built environment? Developing evidence-based healthy built environment indicators for policy-makers and practitioners. Plan. Pract. Res. 2017, 32, 537-555. [CrossRef]

43. Kent, J.; Thompson, S.; Capon, A. Healthy planning. In Planning Australia: An Overview of Urban and Regional Planning; Thompson, S., Maginn, P., Eds.; Cambridge University Press: Cambridge, UK, 2012; ISBN 978-1-107-69624-2.

44. Barton, H.; Thompson, S.; Burgess, S.; Grant, M. The Routledge Handbook of Planning for Health and Well-Being: Shaping a Sustainable and Healthy Future; Routledge: New York, NY, USA, 2015; ISBN 978-1-13802-330-7.

45. ACT Government. Incorporating Active Living Principles into the Territory Plan; ACT Government: Canberra, Australia, 2016.

46. NSW Government. NSW Healthy Eating and Active Living Strategy: Preventing Overweight and Obesity in New South Wales 2013-2018; NSW Government: Sydney, Australia, 2013.

47. Kent, J.; Harris, P.; Sainsbury, P.; Baum, F.; McCue, P.; Thompson, S. Influencing urban planning policy: An exploration from the perspective of public health. Urban Policy Res. 2017, 1-15. [CrossRef]

48. Thompson, S.; Kent, J. Healthy built environments supporting everyday occupations: Current thinking in urban planning. J. Occup. Sci. 2014, 21, 25-41. [CrossRef] 
49. Matan, A.; Newman, P.; Trubka, R.; Beattie, C.; Selvey, L.A. Health, transport and urban planning: Quantifying the links between urban assessment models and human health. Urban Policy Res. 2015, 33, 145-159. [CrossRef]

50. Christian, H.; Knuiman, M.; Bull, F.; Timperio, A.; Foster, S.; Divitini, M.; Middleton, N.; Giles-Corti, B. New urban planning code's impact on walking: The residential environments project. Am. J. Public Health 2013, 103, 1219-1228. [CrossRef] [PubMed]

51. Giles-Corti, B.; Knuiman, M.; Pikora, T.J.; Van Niel, K.; Timperio, A.; Bull, F.C.L.; Shilton, T.; Bulsara, M. Can the impact on health of a government policy designed to create more liveable neighbourhoods be evaluated? An overview of the residential environment project. NSW Public Health Bull. 2007, 18, 238-242. [CrossRef]

52. Freestone, R.; Wheeler, A. Integrating health into town planning: A history. In The Routledge Handbook of Planning for Health and Well-Being: Shaping a Sustainable and Healthy Future; Barton, H., Thompson, S., Burgess, S., Grant, M., Eds.; Routledge: New York, NY, USA, 2015; ISBN 978-1-13802-330-7.

53. Barton, H. City of Well-Being: A Radical Guide to Planning; Routledge: London, UK, 2017; ISBN 978-1-31543-866-5.

54. Buse, K.; Mays, N.; Walt, G. Making Health Policy; Open University Press: Maidenhead, UK, 2001.

55. United Cities and Local Governments. The Sustainable Development Goals: What Local Governments Need to Know; United Cities and Local Governments: Barcelona, Spain, 2015.

56. Australian Local Government Association; National Heart Foundation of Australia; Planning Institute of Australia. Healthy Spaces and Places: A National Guide to Designing Places for Healthy Living. Available online: http:/ / www.healthyplaces.org.au/site/index.php (accessed on 15 September 2014).

57. McCosker, A. Planning for health: Barriers and enablers for healthy planning and design at the local government scale. In Proceedings of the 10th Making Cities Liveable Conference, Brisbane, Australia, 10-11 July 2017; pp. 87-106.

58. Williams, P.; Maginn, P.J. Planning and governance. In Planning Australia: An Overview of Urban and Regional Planning; Thompson, S., Maginn, P.J., Eds.; Cambridge University Press: Cambridge, UK, 2012; ISBN 978-1-10769-624-2.

59. Barton, H.; Grant, M. Urban planning for healthy cities a review of the progress of the European healthy cities programme. J. Urban Health 2013, 90, S129-S141. [CrossRef] [PubMed]

60. Cleland, V.; McNeilly, B.; Crawford, D.; Ball, K. Obesity prevention programs and policies: Practitioner and policy-maker perceptions of feasibility and effectiveness. Obesity 2013, 21, E448-E455. [CrossRef] [PubMed]

61. McCosker, A.; Matan, A. Barriers and enablers to planning initiatives for active living and health. J. Sustain. Dev. 2018, 11, 68-82. [CrossRef]

62. Lawless, A.; Lane, A.; Lewis, F.-A.; Baum, F.; Harris, P. Social determinants of health and local government: Understanding and uptake of ideas in two Australian states. Aust. N. Z. Public Health 2017, 41, 204-209. [CrossRef] [PubMed]

63. Allender, S.; Gleeson, E.; Crammond, B.; Sacks, G.; Lawrence, M.; Peeters, A.; Loff, B.; Swinburn, B. Moving beyond 'rates, roads and rubbish': How do local governments make choices about healthy public policy to prevent obesity? Aust. N. Z. Health Policy 2009, 6, 20. [CrossRef] [PubMed]

64. Thompson, S.; McCue, P. Healthy planning: An evolving collaborative partnership. Urban Policy Res. 2016, 34, 73-89. [CrossRef]

65. Northridge, M.; Sclar, E.; Biswas, P. Sorting out the connections between the built environment and health: A conceptual framework for navigating pathways and planning healthy cities. Bull. N. Y. Acad. Med. 2003, 80, 556-568. [CrossRef] [PubMed]

66. Allender, S.; Gleeson, E.; Crammond, B.; Sacks, G.; Lawrence, M.; Peeters, A.; Loff, B.; Swinburn, B. Policy change to create supportive environments for physical activity and healthy eating: Which options are the most realistic for local government? Health Promot. Int. 2011, 27, 261-274. [CrossRef] [PubMed]

67. Thomas, M.M.; Hodge, W.; Smith, B.J. Building capacity in local government for integrated planning to increase physical activity: Evaluation of the VicHealth MetroACTIVE program. Health Promot. Int. 2009, 24, 353-362. [CrossRef] [PubMed]

68. Corbett, S. The art of the possible: Experience and practice in health impact assessment in New South Wales. NSW Public Health Bull. 2005, 16, 116-118. 
69. Delany, T.; Harris, P.; Williams, C.; Harris, E.; Baum, F.; Lawless, A.; Wildgoose, D.; Haigh, F.; Macdougall, C.; Broderick, D.; et al. Health impact assessment in New South Wales and health in all policies in South Australia: Differences, similarities and connections. BMC Public Health 2014, 14, 699-707. [CrossRef] [PubMed]

70. Thompson, S.; Kent, J.; Lyons, C. Building partnerships for healthy environments: Research, leadership and education. Health Promot. J. Aust. 2014, 25, 202-208. [CrossRef] [PubMed]

71. Giles-Corti, B.; Sallis, J.F.; Sugiyama, T.; Frank, L.D.; Lowe, M.; Owen, N. Translating active living research into policy and practice: One important pathway to chronic disease prevention. J. Public Health Policy 2015, 36, 231-243. [CrossRef] [PubMed]

72. Kingdon, J.W. Agendas, Alternatives, and Public Policies, 2nd ed.; Longman: New York, NY, USA, 2003; ISBN 978-7-30110-272-5.

73. Henstra, D. Explaining local policy choices: A multiple streams analysis of municipal emergency management. Can. Public Adm. 2010, 53, 241-258. [CrossRef]

74. Sabatier, P.A. Theories of the Policy Process; Westview Press: Boulder, CO, USA, 2007; ISBN 978-0-78673-424-5.

75. Craig, R.L.; Felix, H.C.; Walker, J.F.; Phillips, M.M. Public health professionals as policy entrepreneurs: Arkansas's childhood obesity policy experience. Am. J. Public Health 2010, 100, 2047-2052. [CrossRef] [PubMed]

76. Hoeijmakers, M.; De Leeuw, E.; Kenis, P.; De Vries, N.K. Local health policy development processes in the Netherlands: An expanded toolbox for health promotion. Health Promot. Int. 2007, 22, 112-121. [CrossRef] [PubMed]

77. Zahariadis, N. Ambiguity and choice in European public policy. Eur. Public Policy 2008, 15, 514-530. [CrossRef]

78. Nakamura, R.T. The textbook policy process and implementation research. Policy Stud. Rev. 1987, 7, 142-154. [CrossRef]

79. Boswell, C.; Rodrigues, E. Policies, politics and organizational problems. Policy Politics 2016, 44, 507-524. [CrossRef]

80. Exworthy, M.; Powell, M. Big windows and little windows: Implementation in the 'congested state'. Public Adm. 2004, 82, 263-281. [CrossRef]

81. Howlett, M.; McConnell, A.; Perl, A. Streams and stages: Reconciling kingdon and policy process theory. Eur. J. Political Res. 2015, 54, 419-434. [CrossRef]

82. Allender, S.; Cavill, N.; Parker, M.; Foster, C. Tell us something we don't already know or do! The response of planning and transport professionals to public health guidance on the built environment and physical activity. J. Public Health Policy 2009, 30, 102-116. [CrossRef] [PubMed]

83. Thompson, S.; Kent, J.; Lyons, C. Planning and health: Forging new alliances in building healthy and resilient cities. In Proceedings of the Joint European (AESOP) and American (ACSP) Congress, Dublin, Ireland, 15-19 July 2013.

84. Zahariadis, N. Ambiguity and multiple streams. In Theories of the Policy Process, 3rd ed.; Sabatier, P.A., Weible, C.M., Eds.; Westview Press: New York, NY, USA, 2014; pp. 25-58.

85. Thornberg, R. Informed grounded theory. Scand. J. Educ. Res. 2012, 56, 243-259. [CrossRef]

86. Braun, V.; Clarke, V. Using thematic analysis in psychology. Qual. Res. Psychol. 2006, 3, 77-101. [CrossRef]

87. Boyatzis, R.E. Transforming Qualitative Information: Thematic Analysis and Code Development; Sage Publications: Thousand Oaks, CA, USA, 1998; ISBN 0761909605.

88. Smith, M. Integrating policies, plans and programmes in local government: An exploration from a spatial planning perspective. Local Gov. Stud. 2014, 40, 473-493. [CrossRef]

89. Reckien, D.; Flacke, J.; Olazabel, M.; Heidrich, O. The influence of drivers and barriers on urban adaptation and mitigation plans-an empirical analysis of European cities. PLoS ONE 2015, 10, e0135597. [CrossRef] [PubMed]

90. Wiggins, D. Addressing Active Living and Healthy Eating through Councils' Integrated Planning and Reporting Framework; Prepared for the NSW Premier's Council for Active Living: Sydney, Australia, 2013.

91. National Heart Foundation of Australia. 2015 Local Government Awards. 2015. Available online: https:// www.heartfoundation.org.au/images/uploads/main/Programs/LGA_Winners_Book_2015.pdf (accessed on 26 March 2018). 
92. Healthy Active by Design. Healthy Active by Design National Website Launch. Available online: http: / / www.healthyactivebydesign.com.au/news/healthy-active-design-national-website-launch (accessed on 2 May 2017).

93. Saidla, K. Health promotion by stealth: Active transportation success in Helsinki, Finland. Health Promot. Int. 2017. [CrossRef] [PubMed]

94. Grieco, L.A.; Sheats, J.L.; Winter, S.J.; King, A.C. Physical activity behavior. In The Handbook of Health Behavior Change, 4th ed.; Riekert, K.A., Ockene, J.K., Pbert, L., Eds.; Springer Publishing Company: New York, NY, USA, 2013; pp. 179-210. ISBN 978-0-8261-9936-2.

95. Brockman, R.; Fox, K.R. Physical activity by stealth? The potential health benefits of a workplace transport plan. Public Health 2011, 125, 210-216. [CrossRef] [PubMed]

96. Kent, J.; Wheeler, A. What can built environment and health professionals learn from crime prevention in planning? Introducing 'HPTED'. Urban Policy Res. 2015. [CrossRef]

97. Beumer, C. Sustopia or cosmopolis? A critical reflection on the sustainable city. Sustainability 2017, 9, 845. [CrossRef]

98. National Heart Foundation of Australia. Creating Healthy Neighbourhoods: Consumer Preferences for Healthy Development. 2011. Available online: https://www.heartfoundation.org.au/images/uploads/ main/Programs/creating-healthy-neighbourhoods.pdf (accessed on 26 March 2018).

99. Tolley, R. Good for Busine\$: The Benefits of Making Streets More Walking and Cycling Friendly. 2011. Available online: https:/ / www.heartfoundation.org.au/images/uploads/publications/Good-for-business. pdf (accessed on 26 March 2018).

100. Harris, E.; Wills, J. Developing healthy local communities at local government level: Lessons from the past decade. Aust. N. Z. J. Public Health 1997, 21, 403-412. [CrossRef] [PubMed]

101. Giles-Corti, B.; Whitzman, C. Active living research: Partnerships that count. Health Place 2012, 18, 118-120. [CrossRef] [PubMed]

102. Giles-Corti, B.; Foster, S.; Shilton, T.; Falconer, R. The co-benefits for health of investing in active transportation. NSW Public Health Bull. 2010, 21, 122-127. [CrossRef] [PubMed]

103. McMichael, A.J. Will considerations of environmental sustainability revitalise the policy links between the urban environment and health? NSW Public Health Bull. 2007, 18, 41-45. [CrossRef]

104. Sarkar, C.; Webster, C.; Gallacher, J. Healthy Cities: Public Health through Urban Planning; Edward Elgar Publishing: Cheltenham, UK, 2014; ISBN 978-1-78195-572-7.

105. Embrett, M.G.; Randall, G.E. Social determinants of health and health equity policy research: Exploring the use, misuse, and nonuse of policy analysis theory. Soc. Sci. Med. 2014, 108, 147-155. [CrossRef] [PubMed]

106. Thompson, S.; Kent, J. Healthy planning: The Australian landscape. Built Environ. 2016, 42, 90-106. [CrossRef]

107. Harris, P.; Kent, J.; Sainsbury, P.; Thow, A.M. Framing health for land-use planning legislation: A qualitative descriptive content analysis. Soc. Sci. Med. 2016, 148, 42-51. [CrossRef] [PubMed]

108. Thompson, S. A planner's perspective on the health impacts of urban settings. NSW Public Health Bull. 2007, 18, 157-160. [CrossRef]

109. Lerner, H.; Berg, C. A comparison of three holistic approaches to health: One health, ecohealth, and planetary health. Front. Vet. Sci. 2017, 4. [CrossRef] [PubMed]

110. Porter, L. Indigenous people and the miserable failure of Australian planning. Plan. Pract. Res. 2017, 32, 556-570. [CrossRef]

111. Wensing, E.; Porter, L. Unsettling planning's paradigms: Towards a just accommodation of indigenous rights and interests in Australian urban planning? Aust. Plan. 2016, 53, 91-102. [CrossRef]

112. Wilcox, B.; Aguirre, A.; Daszak, P.; Horwitz, P.; Martens, P.; Parkes, M.; Patz, J.; Waltner-Toews, D. Ecohealth: A transdisciplinary imperative for a sustainable future. EcoHealth 2004, 1, 3-5. [CrossRef]

113. Ministry of Health-Manatū Hauora. Whānau ORA Health Impact Assessment. Available online: https:// www.health.govt.nz/our-work/health-impact-assessment/whanau-ora-health-impact-assessment (accessed on 25 February 2018).

114. Gitanyow Chiefs Office. Early Engagement: Land Use. Available online: http://www.gitanyowchiefs.com/ programs / land-use/ (accessed on 25 February 2018).

115. Rydin, Y.; Bleahu, A.; Davies, M.; Davila, J.D.; Friel, S.; De Grandis, G.; Grace, N.; Hallal, P.C.; Hamilton, I.; Howden-Chapman, P.; et al. Shaping cities for health: Complexity and the planning of urban environments in the 21st century. Lancet 2012, 379, 2079-2108. [CrossRef] 
116. Falconer, R.; Giles-Corti, B. Smart development: Designing the built environment for improved access and health outcomes. In Transitions: Pathways towards Sustainable Urban Development in Australia; Newton, P.W., Ed.; CSIRO Publishing: Collingwood, Australia, 2008; pp. 585-597. ISBN 978-0-64309-799-5.

117. Lukez, P. Suburban Transformations; Princeton Architectural Press: New York, NY, USA, 2007; ISBN 978-1-56898-683-8.

118. Raphael, D. Social Determinants of Health: Canadian Perspectives; CSPI: Toronto, ON, Canada, 2004.

119. Browne, G.R.; Davern, M.T.; Giles-Corti, B. An analysis of local government health policy against state priorities and a social determinants framework. Aust. N. Z. Public Health 2016, 40, 126-131. [CrossRef] [PubMed]

120. Whitehead, M.; Dahlgren, G. What can be done about inequalities in health? Lancet 1991, 338, 1059-1063. [CrossRef]

121. Government of South Australia. South Australian Public Health Act 2011; Government of South Australia: Adelaide, Australia, 2011.

122. Government of South Australia. Planning, Development and Infrastructure Act 2016; Government of South Australia: Adelaide, Australia, 2016.

(C) 2018 by the authors. Licensee MDPI, Basel, Switzerland. This article is an open access article distributed under the terms and conditions of the Creative Commons Attribution (CC BY) license (http://creativecommons.org/licenses/by/4.0/). 